\title{
Memoria, prácticas artísticas y espacio público: posibilidades frente al conflicto armado colombiano
}

\author{
Memory, artistic practices and public space: \\ possibilities in the Colombian armed conflict
}

\author{
Santiago Jiménez Mojica \\ Sociólogo, Universidad Santo Tomás \\ jimenez.sociologo@gmail.com \\ Artículo de investigación
}

Fecha de recepción: 11 de noviembre de 2011 • Fecha de aprobación: 2 de febrero de 2012

\section{RESUMEN}

Más allá de sus propósitos estéticos, el arte y la performancia aparecen como formas alternativas de resistencia, concientización y visibilización de fenómenos políticos y sociales que buscan especialmente generar y construir memoria en favor de las víctimas. Enmarcadas en el espacio público, entendido no solo como lugar de encuentro, sino como escenario de pugnas políticas orientadas a la formación de opiniones públicas contrarias a la oficial, han logrado construir memoria colectiva y reivindicar derechos y demandas tradicionalmente subordinados, como puede advertirse en el caso del conflicto colombiano.

Palabras clave: memoria, prácticas artísticas y performativas, espacio público, luchas políticas, relato hegemónico.

\section{Abstract}

Beyond their aesthetic purposes, art and performance appear to be alternative forms of resistance, consciousness and visibility of political and social phenomena that attempt to generate and construct memory in favor of victims. In the context of public space, defined not only as a space for encounters but also as a scenario for political conflict and for the formation of public opinion that contradicts official opinions, it has constructed collective memory and it has reclaimed rights and demands traditionally subordinated, as the Colombian case demonstrates..

Keywords: memory, artistic and performance practices, public space, political struggles, hegemonic narrative. 
La memoria es, sin lugar a dudas, un tema que ha entrado a ocupar un relevante lugar de indagación tanto en los ámbitos académicos como en espacios políticos y sociales de la realidad colombiana, ya que se ha evidenciado su necesidad para la búsqueda de la verdad, con el fin de conducir al conocimiento de los responsables en los sucesos de la fuerte violencia que ha perdurado durante más de medio siglo en el país. Esto, con la intención de buscar acciones de justicia y la no repetición de hechos degradantes y reiterativos propios del conflicto armado. En este sentido, pensar en la memoria va más allá de la evocación del pasado y los recuerdos de hechos particulares, pues implica un ejercicio en el que repasar el presente y las nociones hacia futuro es fundamental para lograr construir perspectivas en las que la violencia deje de ser protagonista de la cotidianidad.

De esta manera, el tema de la memoria gana importancia, especialmente en lugares donde el conflicto y las violaciones a los derechos humanos hacen parte del día a día. A su vez, el arte y las prácticas artísticas, como un ámbito más de la realidad social, han desempeñado un papel importante como alternativa para la configuración de la historia y de la memoria colectiva. Por otro lado, frente a la realidad política y social del país, el tema ha entrado a tener mayor valor en el debate público, y en este, desde el arte y la performancia, se ha intentado dar un lugar a correlatos alternativos frente a las víctimas y los hechos puntuales de violencia; correlatos que aunque a veces se tornan invisibles e incomprensibles frente a la opinión pública, logran explicar, mediante procesos simbólicos, muchos sucesos de la realidad cotidiana de Colombia. Estos correlatos permiten darle otra mirada a aquello narrado por la historia oficial y de esta forma, el arte y la performancia como herramientas alternativas, cargadas de simbolismo, han abierto un espacio para dar a conocer hechos del pasado de una manera diferente (distanciados de aquellos discursos construidos hegemónicamente) para pensar en el presente y construir proyecciones a futuro en las que se evite la repetición de esos sucesos afrentosos.

Las formas como se construye la realidad se encuentran vinculadas a cómo los individuos la percibimos, cómo incidimos para transformarla y, desde aquí, cómo recordamos y elaboramos sentidos del pasado. Los individuos no somos aislados, sino que nos encontramos inmersos en un contexto social que hace que esa construcción de la realidad esté influenciada socialmente, enmarcada en un tiempo y un espacio que también es experiencial en los otros. Por lo tanto, el hecho de recordar algo 
no solo corresponde a lo más íntimo de lo emocional, sino que incluye, a su vez, las relaciones sociales, las cuales se encuentran en estos procesos de rememoración y olvido. Es así como la experiencia de otros actúa en la experiencia propia y es determinante en los procesos de configuración de la memoria.

De allí la pertinencia de las ciencias sociales en el tema de la memoriay, en particular, la sociología, pues sus herramientas le permiten pensar los escenarios sociales en los que se produce el recuerdo y el olvido, al igual que pensar las posibilidades que se dan entre hechos pasados, presentes y su directa interacción e interrelación entre individuos y colectividades, prácticas vividas y transferidas, y pensar, a partir de aquí, cómo se da la construcción de una historia oficial que se ha hecho legítima a través de diversas instituciones oficiales. De acuerdo con esto, desde el papel de la sociedad y las instituciones en la construcción de recuerdos individuales y colectivos se da cuenta de la pertinencia de una sociología de la memoria.

De esta manera, la memoria colectiva se remite a la experiencia que una comunidad o un grupo puede legar a un individuo o grupo de individuos, para que el pasado y los recuerdos que se tienen de este sean un aspecto importante en los procesos presentes $y$ en las nociones a futuro y, a su vez, para que aquellas tragedias o sucesos que han afectado individual o colectivamente a un marco social sean reconocidos, no vuelvan a repetirse y sean un referente para el futuro.

El arte y la performancia, como ámbitos de la realidad social y como representaciones simbólicas de subjetividades y colectividades, permiten problematizar la noción social respecto al pasado, desde una tensión con el presente y con una perspectiva hacia el futuro. A su vez, el arte como una forma de construcción de memoria colectiva tiene grandes posibilidades de transformación mediante la performancia o la narración alternativa implícita en esta; es decir, el arte como una construcción social de recuerdos, que tiene un sentido subjetivo y que atraviesa lo colectivo, dentro de un contexto social y cultural y, al tiempo, como un fenómeno que se establece socialmente y posibilita la transformación de realidades.

Por esta razón, existen ciertas apuestas artísticas, performativas y publicitarias que se han venido realizando en el país, desde hace algunos años, como forma de resistencia, 
concientización y visibilización sobre el problema del conflicto armado; los cuales marcan el acento en la construcción de memoria en favor de las víctimas, procuran el uso del espacio público no solo como un lugar de encuentros, sino también como lugar de disputas que genere una opinión pública alternativa frente a la oficial, y propugnan así por la reivindicación de derechos y demandas que, a partir de esas narrativas alternativas, se alzan como una forma de lucha por esas memorias ocultas.

Jelin (2002) expone cómo en el Cono Sur las transiciones en los conflictos se han dado de manera diferente y singular, pues la forma en que se han generado no ha permitido acuerdos entre quienes participan políticamente de estos problemas; a la vez que los regímenes autoritarios y dictatoriales han utilizado la desaparición forzada como una práctica sistemática que en principio buscaba eliminar cualquier tipo de oposición en este sentido:

Las memorias de los conflictos sociales previos a la instauración dictatorial, así como la crudeza e inmediatez de las violaciones a los derechos humanos durante las mismas, crearon escenarios para la manifestación de confrontaciones, en el marco de un difícil intento de generar consensos entre los diversos actores políticos. Las voces censuradas y prohibidas comenzaron a hacerse oír, pero las voces autoritarias no necesariamente desaparecieron del debate público (p. 47).

Ahora bien, sin desconocimiento de sus particularidades, el caso colombiano guarda esenciales similitudes con la experiencia del Cono Sur, pues ambos corresponden a conflictos de larga duración y con manifestaciones de violencia fuerte y atroz. En los últimos tiempos, la violencia se ha recrudecido, los actores y los escenarios han cambiado, lo que ha tenido fuerte impacto sobre la sociedad civil. Estos cambios han permitido evidenciar, de alguna manera, una sociedad civil en ruptura de los silencios frente a la violencia y frente a la hegemonía. Hegemonía que se ha negado al esclarecimiento de la complejidad de experiencias y relatos en el marco de un conflicto armado interno, el cual viene prolongándose durante aproximadamente medio siglo y en el que se han hecho esfuerzos más de tipo bélico y destructivo que de reparación y construcción, que garanticen la no repetición y, de esta manera, permitan un proceso de recuperación de la memoria y vayan más al fondo de los 
hechos, con examen detallado de las causas que han estructurado y le han dado coyuntura a la violencia en el país.

De acuerdo con esto, es necesario que se brinden espacios a las víctimas para que cuenten lo sucedido, para que señalen las posibilidades de reconstrucción de todo aquello que la violencia les ha arrebatado. Espacios con el fin de hacer una apuesta hacia futuro para que los hechos de violencia nunca más se repitan y para que todas las representaciones sociales que pueden manifestarse simbólicamente, que no necesariamente provengan de las víctimas, también puedan ser apropiadas como pertenecientes a una historia y a un contexto, mediante formas de expresión y de reconstrucción de la memoria;

El pedido del "yo" testimonial no es individual; su intención es hablar en nombre de otros; su experiencia no apela a ser una experiencia individual sino compartida; su historia es también de los otros (Gerassi-Navarro, 1994: 179).

Pese a que el conflicto del país se encuentra abierto, adquiriendo nuevas dimensiones, se han comenzado a operar mecanismos y discursos de justicia transicional; respecto de lo cual ha sido motivo de álgida discusión si dicha transición está realmente ocurriendo en el país y si leyes como la Ley de Justicia y Paz y la Ley de Víctimas contribuyen en verdad a una transformación del conflicto. Sobre esto es importante destacar lo que señala Ceballos Medina (2009):

Los temas y repertorios de la consagrada fórmula trinitaria de Jean Joinet — verdad, justicia y reparación - han permeado en un lapso extraordinariamente corto las prácticas y aspiraciones de innumerables organizaciones sociales, instituciones públicas y agencias de cooperación. Colombia se va amoldando así, sin asumirlo en todas sus implicaciones, y casi por inercia, a un nuevo universo mental de posconflicto que convive con las realidades cotidianas de la guerra, sobre todo en las fronteras y en los márgenes de la nación (p. 7).

En efecto, a pesar de que se trata de mostrar que Colombia está en un periodo de posconflicto, en el que los paramilitares ya no hacen parte de la realidad colombiana y en el que se afirma desde el poder que las Fuerzas Armadas están a punto de darle 
el puntillazo final a la guerrilla de las Fuerzas Armadas Revolucionarias de Colombia (FARC), la realidad, no siempre mostrada por los medios de comunicación, es que la guerra y el conflicto armado siguen vigentes y, lejos de su resolución, existe una redimensión del conflicto y un reagrupamiento de los grupos armados ilegales. De allí el cuestionamiento a la llamada justicia transicional, pues su realización supone que los abusos y violaciones a los derechos humanos de sociedades fracturadas deben tomarse en consideración dentro de una política de transformación para la restauración de la justicia, la reconciliación y la no repetición, en función de asegurar el mantenimiento de la paz.

Esto resulta importante, en primer lugar, porque nos aproxima al contexto actual del conflicto en Colombia y a algunas respuestas que desde el Estado se le han dado, lo cual permite anticipar las posibilidades que frente al tema de la memoria se pueden dar a la hora de la búsqueda y el esclarecimiento de la verdad y del conocimiento de quienes han sido víctimas, es decir, las posibilidades de tener a la memoria como un referente para la no repetición y en contra del olvido. En segundo lugar, porque permite advertir algunas dificultades existentes en las disputas por darle un lugar a la memoria y a la indagación de la verdad de personas directamente afectadas por el conflicto y del resto de la sociedad colombiana.

Por lo anterior, hablar de memoria en lugares donde el conflicto, la violencia y las violaciones a los derechos humanos siguen vigentes deviene en una tarea compleja, debido a que dentro de este marco social la elaboración y el trabajo que debe hacerse para incorporar memorias resulta limitado (dado que hay información que buscará ocultarse) e incluso peligroso, pues las disputas que se dan en el marco político para dar a conocer sucesos velados de la historia y buscar que estos se posicionen mediante diferentes alternativas en escenarios del país, puede traer consigo detracción y problemas que hacen que temporalmente estos relatos pierdan fuerza.

De esta forma, la temporalidad tiene un sentido muy fuerte sobre la memoria, pues pasado, presente y futuro se encuentran en juego allí. Jelin (2002) al respecto lo plantea como una temporalidad compleja, pues a esas variables de tiempo se le debe agregar la existencia de múltiples subjetividades, las cuales se van construyendo a través de un proceso histórico en el cual, como lo menciona Aldana (2009), "el presente 
contiene y construye la experiencia pasada y las expectativas futuras" (p. 12). Para tal efecto, las experiencias del pasado se encuentran influenciadas por un horizonte de expectativas, es decir, por una temporalidad futura. Además, esas experiencias del pasado pueden incorporar no solo vivencias propias, sino también las de otros que ya han sido transmitidas, razón por la cual el pasado puede condensarse o expandirse, de acuerdo con la incorporación de dichas experiencias del pasado.

La construcción de memoria implica procesos de significación o resignificación de subjetividades en disputa. Esto, si se entiende que a partir de la experiencia de cada individuo, en el diálogo y en el compartir las propias vivencias con los otros, se van construyendo y transformando nuevos sentidos en las relaciones; a la par, el cambio en los procesos de la historia, cambios coyunturales en términos políticos y sociales, pueden ser de gran influencia en la modificación de cómo se interpretan las experiencias del pasado y la construcción de expectativas para el futuro.

En este sentido, el problema del actual conflicto armado en el país le impone ciertas limitaciones al trabajo de la reconstrucción de la memoria, ya que si el conflicto armado prevalece y, por un lado, las estructuras armadas ilegales siguen teniendo gran influencia dentro del territorio nacional y, por otro, las violaciones a derechos humanos por parte de estas estructuras, como también de las oficiales, continúan diariamente en la realidad colombiana, entonces acercarse a nociones importantes en la reconstrucción de la memoria — como lo es dar respuesta a cómo han sucedió los hechos, quiénes han sido la víctimas y quiénes los responsables - se convierte en una labor cada vez más compleja, dada la magnitud y continuidad del conflicto en el país.

A pesar de las limitaciones que enfrenta la incorporación de las memorias en Colombia, resulta importante mencionar que existen organizaciones, colectivos, movimientos e incluso subjetividades que disputan un lugar para inscribir esas memorias, para evitar que se sigan reduciendo al olvido, para que puedan permitir pensar perspectivas hacia futuro, para impedir la repetición de estos hechos afrentosos y para buscar de salidas al conflicto que aún perdura. Allí, en el lugar de estas disputas, se encuentran diferentes experiencias como apuestas alternativas, incluidas manifestaciones artísticas y performativas, para dar a conocer sucesos de la realidad que muchas veces están ocultos. De ahí el interés desde la sociología por dar cuenta de la inserción de esas 
disputas políticas, por la memoria y por analizar el impacto y la importancia que estas puedan tener en una sociedad que continúa en conflicto.

En este sentido, al hacer referencia al tema de la memoria y su relación con el arte y el espacio público, es importante mencionar que, en escenarios como el del país, plasmar memorias cuya interpretación sigue siendo materia de pugnas en el presente resulta ser una tarea que a veces se presenta difusa e incluso peligrosa:

La acción de fijar el recuerdo mediante monumentos o inscripciones supone un afán definitivo que a menudo entra en conflicto con una historia que para algunos actores continúa estando viva y no puede, todavía, "sellarse” en verdades últimas (Schindel, 2009, p. 69).

De esta forma, los individuos, grupos, colectivos y movimientos sociales que han querido asumir desde diferentes manifestaciones la construcción de una memoria colectiva lo han hecho a través de diversas estrategias, en diversos escenarios y con diversas intenciones, lo cual entra en fuertes controversias con intereses hegemónicos propios de una historia que no quiere permitir que se conozcan verdades del conflicto ni los correlatos y testimonios ocultos. Estas acciones se presentan como disputas políticas que hacen referencia a un proceso en el que actores sociales entran en conflicto. Estas disputas, en ocasiones, están basadas en demandas que se expresan de manera pública, buscando exigencias y reivindicaciones. Al respecto, Tilly (1998) afirma que las luchas políticas se dan por reclamaciones que buscan la reivindicación de algunos sucesos, derechos o sectores de la sociedad:

El conflicto político incluye todas las ocasiones 1) en las que algún grupo de personas realiza reivindicaciones colectivas públicas visibles sobre otros actores (reivindicaciones que si se cumpliesen afectarían a los intereses de estos últimos) y 2) en las que al menos una de las partes afectadas por reivindicaciones, incluyendo terceras partes, es un gobierno. Por lo tanto, el conflicto político abarca revoluciones, rebeliones, guerras, conflictos étnicos, movimientos sociales, genocidio, campañas electorales, la mayoría de huelgas y cierres patronales, parodias públicas, incautaciones colectivas de mercancías, y muchas otras formas de interacción (p. 30). 
Dentro de este concepto de disputas políticas, la cultura cumple una labor social fundamental, pues desde allí es posible comprender e interpretar los significados (proceso simbólico) que supone una lucha entre diversas interpretaciones que buscan dar nuevas definiciones del poder social y dar a conocer nuevos significados, diferentes a los dominantes, como una disputa por la interpretación (Pinto, 2009).

De acuerdo con lo anterior, para comprender mejor la noción de "luchas políticas", es importante señalar que en las disputas por dar nuevas definiciones y nuevos significados desempeñará un papel importante la legitimidad y la hegemonía, pues "son dos formas de analizar la aceptación de la dominación y por ellos hacen parte preferencial de la disputa política, ya que tanto movimientos sociales como partidos políticos ponen en juego controversias políticas y luchas por el significado” (Pinto, 2009, p. 386).

En este campo de luchas por las memorias existen personas, movimientos sociales e instituciones públicas que buscan reclamar y llamar la atención del público hacia asuntos afrentosos, para que de esta manera puedan hacerse visibles y a su vez puedan generar en la opinión pública constantes que animen el repudio contra la repetición de estas situaciones. Estas luchas se dan en diversos escenarios y a pesar de ello, para que estas puedan provocar debate y atención frente al público en general, especialmente cuando no existe legitimidad y reconocimiento en estas pugnas (puede ser que para lograr convertirse en una cuestión pública), sea necesario un proceso de larga duración y de mucha perseverancia, es decir, un proceso en el que "tiene que haber alguien que lo promueve, que empuja y dirige sus energías al fin deseado" (Jelin, 2002, p. 49).

Ahora bien, la importancia que tienen aquellos que están en disputa por las memorias se da en términos de la dinámica que puede generar memoria y opinión pública, pues a pesar de que no todos los individuos comparten los mismos recuerdos y olvidos ni tampoco la misma ideología, lo que se busca muchas veces en estas pugnas es el reconocimiento y la aceptación de los hechos, la búsqueda por la verdad, por la justicia y por la no repetición. Al respecto afirma Jelin (2005):

Las luchas para definir y nombrar lo que tuvo lugar durante periodos de guerra, violencia política o terrorismo de estado, así como los intentos de 
honrar y recordar a las víctimas e identificar a los responsables, son vistas por diversos actores sociales (incluyendo intelectuales y analistas del tema) como pasos necesarios para asegurar que los horrores del pasado no se puedan repetir (Nunca más) (p. 232).

A pesar de las luchas por hacer de la memoria y del pasado una parte esencial del presente y de los esfuerzos de organizaciones y movimientos sociales por obtener justicia y reconocimiento de los hechos, es evidente que para aquellas víctimas de violaciones de sus derechos humanos tales acciones no han tenido tanto éxito, especialmente en el Cono Sur, donde se han propuesto y promulgado leyes convenientes para perpetradores de crimenes y violadores de derechos humanos, quienes, en ellas amparados, terminan muchas veces cobijados por amnistías. Para aquellos "emprendedores de la memoria"1, la no repetición implica, en primer lugar, la investigación y el esclarecimiento de las violaciones a derechos humanos y de los hechos de violencia ocurridos durante un conflicto y, en segundo lugar, el castigo a los perpetradores y responsables de esos crímenes. Estas acciones buscan justicia.

Estas luchas políticas, orientadas a generar opinión pública mediante su posicionamiento en el espacio, se presentan como acciones de denuncia, al tiempo que buscan contribuir al esclarecimiento de la verdad, el conocimiento sobre las víctimas y sobre sus restos en los casos de la desaparición forzada. Estas denuncias y búsquedas de la verdad deben conducir a acciones de la justicia que saquen a la luz pública a los responsables y perpetradores de violaciones de los derechos humanos. Por último, estas luchas buscan hacer visibles actos violentos que la gran mayoría de veces están ocultos, para de esta manera ampliar la conciencia sobre estos acontecimientos.

1 Expresión acogida por Elizabeth Jelin, tomada del sociólogo norteamericano Howard Becker, quien la propuso para referirse al tema de la desviación social, sosteniendo que en el proceso de generación y enmarcación de conductas desviadas debe haber alguien que se haga cargo de llamar la atención sobre estas desviaciones, a medida que van surgiendo, a fin de crear una constante. Becker llama a este grupo "moral entrepreuners", es decir, empresarios morales. Jelin toma la expresión y la usa para referirse a aquellos que son promotores e impulsores para que las memorias sean visibles, y los llama "emprendedores de la memoria". 
En esas diversas intenciones, uno de los aspectos primordiales de las luchas políticas es posicionar esas memorias en el espacio público; correlatar alternativamente lo que está sucediendo, impugnar los relatos oficiales; por que esa valoración del pasado obtenga el reconocimiento de la opinión pública; por brindarle importancia a su inscripción y permitir su posicionamiento dentro de una marcación territorial. Schindel (2009) lo explica de este modo:

La instalación de monumentos, placas o recordatorios, así como el tratamiento que se da a los sitios que fueron escenario de la violencia, son un modo en que se ejercen y plasman las memorias así como los conflictos asociados a ellas (p. 66).

De esta manera es posible evidenciar cómo estas pugnas insertas en el espacio público buscan incidir deliberadamente en asuntos políticos, es decir, van más allá del acto de rememorar un suceso y se enmarcan en acciones e iniciativas para poner en marcha un proyecto con nociones claras hacia el futuro.

La producción y reproducción simbólica hacen parte de un ámbito social y, como tales, constituyen un elemento importante para involucrar situaciones en las que la sociedad reconozca y refiera hechos que han ocurrido en su seno. En ese sentido, representar un acontecimiento en palabras, imágenes, performances o cualquier tipo de manifestación artística, que le dé un valor a la construcción de la memoria colectiva y entre a disputar dentro del campo de la legitimidad una lucha política para el reconocimiento de sucesos que son invisibles y pasan desapercibidos frente a la opinión pública, se presenta como una posibilidad de correlatar alternativamente pugnas frente a los relatos hegemónicos. Correlatos en los cuales individuos y colectividades buscan espacios diferentes a los oficiales, para dar a conocer estos sucesos, replantear el pasado y cuestionar aquellos mecanismos habituales que construyen dictámenes de lo que sucede en un contexto particular, a través de medios privados que dan a conocer ciertos hechos desde la perspectiva oficial.

Las prácticas y representaciones artísticas han ocupado un lugar permanente durante la configuración de la historia y, en ese sentido, en la configuración de la memoria colectiva. La literatura, las artes visuales, el cine, las artes escénicas y la música, entre otras, han ocupado un lugar central en la construcción de procesos simbólicos; en 
la cultura, debido a lo cual siempre han existido diversas formas de presentación y representación que no solo han llegado a tener reconocimiento y posicionamiento, porque se presentan en museos o en casas de arte, sino también manifestaciones que de alguna manera, más allá de las discusiones sobre lo estético y lo bello en el arte, deben tener un posicionamiento y un lugar en galerías:

\begin{abstract}
Recurren a materiales y procedimientos artísticos como parte de una intervención más directamente política. Estas últimas pueden haber sido generadas por iniciativa de artistas, pero el sujeto que efectivamente las produce se torna masivo y anónimo, se instalan en lugares públicos (plazas o calles) y adquieren visibilidad social como parte de movilizaciones por los derechos humanos (Jelin y Longoni, 2005, pp. 11-12).
\end{abstract}

Este tipo de intervenciones y expresiones que recogen motivaciones colectivas se dan para contar algo frente a los relatos que se posicionan como oficiales generalmente oficiados por quienes tienen la capacidad más amplia de generar opinión pública en la sociedad: los medios masivos de comunicación.

Estas intervenciones sobre las que algunos individuos o movimientos sociales buscan relatar de forma alternativa un suceso se dan en el marco de un contexto social; por lo tanto, se realizan por un individuo o una colectividad que no puede ser visto como pasivo, sino como partícipe dentro de un entramado particular. Las formas artísticas alternativas han permitido abordar los hechos de una realidad a partir de formas performativas en las que se narra y, de alguna manera, se ofrece otra mirada de lo que ha sucedido o sucede, buscando posicionarse y generar opinión, acudiendo a las calles, parques, plazas y espacios donde los transeúntes son múltiples, para contar otras perspectivas, otras lecturas, otras sensaciones, en su mayoría contrarias a los relatos oficiales y a las narraciones impuestas desde el poder y determinantes sobre cómo se debe opinar y recordar. De esta manera, las manifestaciones artísticas y performativas se dan como una lucha política frente al olvido y como una forma de resistencia. Sobre este tipo de arte Aldana (2009) señala:

Es así como desde el arte, un arte más ligado con lo cotidiano y lo popular que con la estrechez de las reglas artísticas, que se re-configuran recuerdos 
individuales y colectivos que miran de otra forma al pasado, buscando alejarse de construcciones hegemónicas en la proyección de un futuro más cercano a las necesidades e identidades de los grupos que recurren a él (p. 25).

Así, las manifestaciones artísticas como alternativas para hacer visibles hechos relevantes, que ante la cotidianidad pasan desapercibidos debido al poder y a la influencia del relato oficial y de quienes se encargan de contarlo, se dan generalmente en escenarios en los que los sistemas democráticos carecen de fortaleza y en los que en el conflicto se presentan fuertes cargas de poder que, primero, no permiten que se brinde un reconocimiento en la sociedad de sucesos que deberían ser conocidos, segundo, no evidencian los daños ocasionados a las víctimas de este conflicto y, por último, no revelan a sus perpetradores. Esta debilidad democrática, de alguna manera, se convierte en generador de una cultura de la impunidad, del olvido y, por lo tanto, de la invisibilidad de las víctimas y los sectores afectados y vulnerados, ya que abre la posibilidad de que esos hechos puedan seguir repitiéndose en la medida en que se les desconozca.

Por ello, es de suma importancia garantizar que los hechos violentos no se repitan y que la sociedad reconozca como imperativo lo sucedido, para poder aprender de la historia y construir sus memorias colectivas sobre los principios de verdad y justicia. Por esta razón, el arte y lo simbólico llegan a ocupar un lugar en la construcción de la memoria, pues "el arte cuestiona los mecanismos tradicionales que obligan a recordar a la mayoría de la opinión pública la forma en que sucedieron determinados sucesos y la responsabilidad de los agentes involucrados en ellos" (Aldana, 2009, pp. 24-31).

Ahora bien, al hablar de manifestaciones artísticas concernientes a la memoria, se puede hacer referencia a una noción muy amplia al respecto. Sobre esto existen distintos formatos, modos de presentación y representación y distintos espacios de expresión, divulgación y circulación de dichas manifestaciones, las cuales no se restringen a galerías, museos, teatros, etc., sino que, aunque no legitimadas como arte, encuentran un lugar muy empático dentro de lo popular, al recurrir a materiales y procedimientos artísticos como parte de una expresión política. Estas manifestaciones artísticas han ocupado un lugar muy afianzado en los procesos de memoria y tienen un componente que sobrepasa los límites del arte como 
una expresión individual, pues estas expresiones, al insertarse en las calles, en los parques, en las plazas públicas y en otros espacios, permiten que el alcance sea mayor e incluso masivo, con el fin de adquirir una mayor visibilidad para la sociedad, como una forma de exigibilidad, de denuncia y de no callar, para que hechos afrentosos y violentos no queden en el olvido, para que se organice algún tipo de movilización.

Por otro lado, el arte dentro de la construcción de memoria colectiva tiene otra dimensión, en la medida en que el arte puede presentar el sufrimiento y las experiencias en las cuales se ha dado tortura, desaparición, muerte, desplazamiento, persecución y exilio, entre otras formas de violencia; es decir, genera una dimensión sobre los testimonios personales y colectivos que se presentan a través de estas manifestaciones. Esto tiene importancia en cuanto existen obstáculos y trabas para lograr que el testimonio de alguien que se ha visto vulnerado pueda manifestarse para relatar su experiencia. Esto es comprensible porque ante tales situaciones se puede presentar lo que Jelin (2002) denomina como "huecos simbólicos de lo traumático", los cuales se enmarcan en los límites de lo que una víctima puede decir. En ese sentido, desde lo ocurrido en la Segunda Guerra Mundial, en Auschwitz, el testimonio desde múltiples manifestaciones que no solo se remiten al arte se ha prestado como un vehículo y una forma de contar la tragedia.

De esta manera, "el testimonio como construcción de memorias implica multiplicidad de voces, circulación de múltiples 'verdades', también de silencios, cosas no dichas" (Jelin, 2002, p. 96). En este sentido, las manifestaciones artísticas, literarias y performativas encaran de una forma particular el relato y el testimonio frente al sufrimiento y la represión. Esto es también una manera de expresar lo que se siente, de procesar el conflicto y el trauma, de volver decibles los sentimientos, que a veces son difíciles de expresar y que pueden materializar algunas necesidades y dificultades que se presentan colectivamente para reivindicar la lucha por las memorias.

Ahora bien, una de las mayores contribuciones que puede hacer el arte a la construcción de memoria colectiva es la de representar el mundo de otra manera, narrado desde otras voces, para que esas narraciones y correlatos impregnen la historia y la sociedad. Por tal razón es posible afirmar que desde el arte se puede 
crear una visión transformadora del mundo, pues al igual que otros ámbitos que hacen parte de la realidad social, desempeña un papel que se encuentra conectado con otras esferas. Las manifestaciones artísticas que se toman el espacio público como un medio estratégico de resistencia, de quienes tienen la dificultad de insertar sus memorias en espacios privados, den a conocer una reconstrucción del pasado y propongan, a su vez, un lugar y un espacio en el que la performancia hable de aquellas interpretaciones y sucesos de esas voces silenciadas y ahogadas.

Las manifestaciones artísticas como una vía alternativa frente al hermetismo de medios oficiales - que por su condición de privados son de acceso e incidencia restringidos para unos pocos- se presentan como una forma no solo de denuncia, sino también como forma de expresión y de no olvido. Estas manifestaciones buscan posicionarse en lugares de fácil entrada y desean ser generadores de una opinión pública diferente a la producida por los medios; sin embargo, el lograr posicionar estos actos performativos y alternativos resulta ser una tarea difícil para los “emprendedores de la memoria", más aún cuando el escenario de conflicto es persistente. Al respecto Aldana (2009) afirma:

\section{El arte por sí solo no puede cambiar el mundo. Tal vez su mayor contribución sea la de hacer ver el mundo de otra manera, ver lo cotidiano como extraordinario y traer otras voces, diferentes a las ya conocidas, para que hablen sobre sus propias y particulares historias (p. 30).}

Dos experiencias exitosas latinoamericanas que pueden ejemplificarlo fueron aquellos ocurridos en dos países del Cono Sur, en los cuales, mediante actos masivos de performancia, buscaron su posicionamiento en el espacio público, emprendieron y ejercieron luchas políticas por la memoria, luchas para narrar alternativa y simbólicamente. El primero de ellos se desarrolló en Argentina en la década de los años ochenta y se denominó Siluetas, pero es más conocido como El Siluetazo; el segundo se llevó a cabo en Perú, en el 2000, y se denominó Lava la Bandera.

El Siluetazo surge a partir del Proceso de Reorganización Nacional, que fue como se denominó la dictadura militar argentina entre 1976 y 1983, luego del golpe de Estado que derrocó al gobierno de María Estela Martínez de Perón, para subir al 
poder a una junta militar liderada por comandantes de las fuerzas armadas, quienes implantaron el régimen más violento de toda la historia de Argentina. En esta época fueron frecuentes el terrorismo de Estado, la desaparición forzada, los asesinatos de miles de personas, el robo frecuente y sistemático de recién nacidos, la gran cantidad de violaciones a los derechos humanos y otros crímenes de lesa humanidad propiciados por la dictadura.

El 21 y 22 de septiembre de 1983, en Buenos Aires, Argentina, en tiempos de dictadura, mientras se realizaba la Tercera Marcha de la Resistencia por iniciativa de tres artistas plásticos, se llevó a cabo una acción masiva, performativa y de un remarcado carácter político, que en ese momento se dio a conocer como Siluetas y que luego fue más conocido como El Siluetazo. Sobre esta acción colectiva Jelin y Longoni (2005) describen:

Miles de manifestantes se abocan a la producción de siluetas de tamaño natural, como forma de representar "la presencia de la ausencia", la de los miles de detenidos desaparecidos, denunciada y reclamada con las consignas, "con vida se los llevaron, con vida los queremos" y "aparición con vida” (p. 69).

Los participantes de esta acción estética y performativa en la Plaza de Mayo y en sus inmediaciones dibujaron miles de siluetas de hombres, mujeres y niños para rememorar a todas aquellas víctimas desaparecidas en la dictadura. Algunas de esas siluetas venían con inscripciones de nombres de desaparecidos, fechas de desaparición y consignas al respecto. Durante toda la noche "se pegan las siluetas (de pie, nunca yaciendo en el piso, por estricto pedido de las Madres de la Plaza de Mayo)" (Jelin y Longoni, 2005, p. 69), recurriendo a lugares del espacio público como fachadas de casa y edificios, columnas, cabinas de teléfonos, postes, árboles y kioscos, en las cuales no se hizo necesario hablar mucho para enviar un mensaje claro sobre lo que estaba ocurriendo en el país y, adicionalmente, en el que este acto simbólico, que se transformó en acto masivo, se convirtió en denuncia de muchas personas y en un acto de no olvido de los miles de desaparecidos durante una dictadura que seguía en curso.

Algo que siempre estuvo presente en El Siluetazo fue la discusión de si realmente esta práctica podía inscribirse en lo que se conoce como arte: "Para justificarlo, 
se puede inscribir El Siluetazo dentro de cierta genealogía de prácticas artísticas contrahegemónicas que cuestionan la carencia de función social del arte moderno" (Longoni y Bruzzone, 2008, p. 41). En ese sentido, esta acción performativa, aunque no fue presentada por los promotores como arte y que, por lo tanto, en el instante en que se desarrolló no fue leída como tal, pues era considerada como una forma visual de lucha y de memoria, puede presentarse, como dice Longoni y Bruzzone, como una acción que

pone en cuestión la condición moderna del arte al socializar la producción, al buscar una inserción distinta a los restringidos circuitos artísticos. [...] Quizá deba atribuirse a la propia radicalidad artística del proyecto el hecho de que su estatuto artístico haya quedado invisibilizado para la historia del arte durante tanto tiempo (p. 43).

La intervención y participación de tantas personas manifestando mediante este acto de las siluetas — el cual no necesitaba de voz y de arengas para que fuera comprendido en el contexto argentino de la época - fue fundamental en la elaboración de esta performancia, ya que si no se hubiera tornado masiva, entonces no habría tenido la fuerza y la visibilidad necesarias para volverse un símbolo, para entreverse y generar opinión pública.

Por otra parte, en otro contexto, se realiza la acción Lava la Bandera, que ocurrió durante el 2000 en Lima, Perú, de doce del mediodía a tres de la tarde, todos los viernes en la Plaza Mayor, donde una gran cantidad de personas se apropiaban del lugar para públicamente lavar la bandera peruana, en un ambiente de denuncia y de protesta, pero también de resiliencia:

Con el pasar de los primeros días, las colas fueron incrementándose y mucha gente de diferentes clases sociales asistió a la mencionada Plaza con el objetivo de expresar así su indignación frente al régimen (Vich, citado en Jelin y Longoni, 2005, p. 79)

En frente de la sede central de gobierno peruano, en plena plaza pública, las banderas eran lavadas, exprimidas y luego colgadas en tendederos de ropa, como una forma de 
protesta y de indignación frente a los grandes problemas de corrupción del gobierno del ex presidente Alberto Fujimori ${ }^{2}$, que se consolidó en un régimen de diez años. Por tal razón, los peruanos salieron a manifestar mediante este emblema de denuncia "una especie de 'vuelta a la vida' a partir de un nuevo bautismo ciudadano. Era cierto, en aquellos momentos la patria estaba más sucia que nunca, putrefacta” (Vich, citado en Jelin y Longoni, 2005, p. 79).

La manifestación performativa Lava la Bandera se dio como un acto de presión muy fuerte de la sociedad civil a todo lo que sucedía en el país. Se encontró en esta acción una manera de manifestar su inconformidad contra un régimen dictatorial, asociado a las mafias; a su vez, una manera de hacer resistencia a la desaparición forzada, a la corrupción; en otras palabras, era una manera de hacer visible, ante la opinión pública, la realidad política del Perú. Con el transcurso de los días, esta iniciativa fue sumando gente hasta el punto de convertirse en una protesta masiva.

En este sentido, el acto de lavar la bandera en la plaza pública, donde se encuentra representada la centralidad del poder, se convirtió en una alternativa para evidenciar la crisis política y social que estaba viviendo el país, como forma de resignificar la nación y, además, de mostrar "que la construcción del sujeto ciudadano se encuentra inevitablemente atravesada por lo simbólico y lo político" (Vich, citado en Jelin y Longoni, 2005, p. 82).

Ahora bien, como se mencionó con anterioridad, este artículo es producto de una investigación sobre las prácticas artísticas y performativas como posibilidades para hacer memoria en medio del conflicto armado, que ha sido de larga duración en Colombia. Por ello, se investigó el trabajo puntual de Teatro Efímero, que surge entre 2003 y 2004 en Altos de Cazucá, Soacha, debido a una gran preocupación de los miembros de la Fundación Cultural Rayuela por la violencia y la gran cantidad

2 Fujimori duró en el poder desde 1990 hasta el 2000, año en el cual, al verse acorralado por diversos escándalos durante su gestión, huyó a Japón y desde allí renunció a su cargo. En estos momentos se encuentra cumpliendo condena de veinticinco años de cárcel por crímenes de lesa humanidad y delitos de corrupción. A todos estos delitos se suma la figura de Vladimiro Montesinos, quien se desempeńó como la cabeza principal de los organismos de seguridad peruanos, de quien se dice es responsable en la formación del grupo paramilitar Colina, que efectuó terribles operativos de desaparición y asesinato en el Perú. 
de homicidios que se presentaban cotidianamente en ese lugar. Frente a esta cotidianidad nace la iniciativa de reaccionar ante todo lo que estaba sucediendo en ese contexto, dado que la mayoría de organizaciones de derechos humanos que trabajaban allí solo se limitaban a poner la denuncia frente a las instancias legales. La Fundación Cultural Rayuela, a pesar de sentir que esas acciones eran importantes, era consciente de que estas no tenían la contundencia y la fuerza de visibilización de todo aquello que estaba ocurriendo en el sector, pues era bien sabido que la gran mayoría de denuncias nunca terminaban en nada. De esta reflexión surge Teatro Efímero.

Así fue como empezaron a enfocarse en un problema del sector. En 2003 se visibiliza un grupo armado ilegal que hacía presencia en la zona, generando miedo y zozobra dentro de la población, y por medio de amenazas y violencia imponía su propia ley, prohibiendo transitar más tarde de las ocho de la noche, estar en los parques, vestirse con ropa ancha, con ropa negra, etc.; por esta razón, Rayuela empezó a pensar en una acción que fuera colectiva y, además, entendida como un acto de desobediencia y resistencia, en la que se pudiera estar en aquellos lugares prohibidos a las horas prohibidas. Fue así como convocaron a muchos jóvenes de diferentes barrios y sectores populares de Bogotá y de Soacha, jóvenes que en su mayoría habían estado vinculados a experiencias colectivas como el rap, la danza, la ecología, la religión, a quienes se les contó puntualmente lo que estaba sucediendo en Altos de Cazucá y la importancia de la realización de una acción en defensa de la vida.

Con esta labor lograron juntar a quinientos jóvenes, con los cuales se empezó a hacer un trabajo con talleres de artes escénicas, en los que se formó incluso políticamente, tratando de que los actos de desobediencia y resistencia fueran una acción con sentido y no solo el hecho de "estar ahî", ya que para Rayuela era claro que esa acción conllevaba riesgos y que para estar allí, tal y como se los había transmitido la Guardia Indígena, se necesitaba de una fuerte formación espiritual, conocer el contexto, saber qué era lo que estaba sucediendo en Cazucá, al igual de que los jóvenes entendieran muy bien qué era lo que estaba en juego en esa acción. Fue así, después de una larga preparación, cuando sintieron que los jóvenes ya se habían arraigado a esta iniciativa, para al fin decidir llevarla a cabo, tomándose el lugar. Entonces se hizo una primera acción en la que recorrieron los parques y las calles por donde "no se podía andar"; quinientos jóvenes vestidos todos de negro con una máscara blanca, caminando las 
calles en silencio, como una procesión, como inspirada de la secuencia del video musical de The wall, de Pink Floyd, en la que todos están vestidos iguales y marchan en rítmicos y automáticos movimientos hacia una gran máquina de moler que los tritura y los convierte a todos en carne de salchicha.

A raíz de que esa acción fue cubierta por la prensa, se abrió la posibilidad de contar lo que estaba pasando en estos barrios por los noticieros, lo cual le dio mayor valor a la acción, pues permitió que esas voces fueran amplificadas. A partir de ello, la labor de Teatro Efímero empieza a llenarse de sentido y su acción empieza a multiplicarse y a ser llevada a otros barrios marginales de Bogotá, en los que también se empezaban a montar pequeños observatorios de conflicto. Estas acciones se generaron en muchísimos lugares; luego, gente de otros lugares del país empezó a interesarse en ese trabajo y poco a poco se fue abriendo la posibilidad de hacer teatro, pero un teatro más cercano al performance.

Otra acción muy importante de Teatro Efímero, que con el tiempo se ha convertido en un símbolo de las víctimas en el país, ha sido la de los ladrillos, la cual comenzó en Soacha en el marco de unas iniciativas juveniles en las que se hicieron aproximadamente doscientos carteles funerarios que se pegaron en el suelo y en cada uno de los cuales se inscribía el nombre de una víctima, de algún joven asesinado en las lomas, la fecha en la que murió o desapareció, el barrio en el que falleció y si este había sido víctima de asesinato o desaparición.

Esta acción provocó un impacto sobre la población, que al ver los carteles empezó a reconocer familiares, a ponerle nombre a los NN, porque el lugar y la fecha coincidían, y así más gente empezó a dar nombres de familiares que no estaban allí. De esta manera, se hicieron cada vez más carteles, testimonio de la potencialidad de esta acción, pues en primer lugar tienen una fuerte capacidad de demanda y conmoción y, en segundo lugar, se convierten en un modo de documentar lo que estaba ocurriendo con las víctimas y sus historias de vida.

De ahí surgió la idea de pegar los carteles a ladrillos blancos por tres razones: primero, porque los carteles, al estar pegados al piso, se despegaban fácilmente; segundo, pensando en la idea de que "si nos descuidamos vamos a ser un ladrillo más en la pared", 
como dice la aludida canción de Pink Floyd, o también "un ladrillo puede contar de una manera distinta para construir el país que queremos"; y finalmente, porque los ladrillos ganaban volumen, $y$ al hacer algo en la calle es muy importante que tenga mucho grosor para hacer más visible la acción y, también, para hacer algo con estos monumentos. De esta manera, intentaron llevar la acción a Altos de Cazucá y no funcionó, porque a la gente le generaba miedo participar de la acción, así que surgió la idea de llevarla a la Plaza de Bolívar, en el marco del Día Internacional de los Derechos Humanos, y consiguieron el permiso por la Alcaldía Mayor de Bogotá para poner los ladrillos desde la una de la tarde hasta las siete de la noche un 10 de diciembre, con el siguiente eslogan: "Por vida y dignidad, hablemos de verdad".

El evento tuvo tal magnitud y potencia que aproximadamente a las diez de la noche, en la Plaza de Bolívar había cerca de 3.000 personas poniendo velas y haciendo altares; dado que quitar los ladrillos se hacía imposible, hablaron con la Alcaldía y concordaron que no quitarían el monumento en esa noche. A la mañana siguiente fueron nuevamente a la Plaza de Bolívar y los ladrillos seguían ahí; por tal razón, acudiendo a la performancia, empezaron a hacer teatro y a llamar para que enviaran coronas a ese lugar. Así, los ladrillos con coronas y pedestales estuvieron durante treinta y tres días, en los cuales acudieron miles de personas a denunciar, a hablar de sus muertos, a hacer memoria de los hechos de violencia que ocurren en el país, pero también a reflexionar sobre las víctimas y la realidad.

Cuando esa acción comenzó en la Plaza de Bolívar, era un 10 de diciembre de 2005 con 600 ladrillos, con nombres de jóvenes asesinados en las lomas de Bogotá, y luego de más de un mes, el 13 de enero de 2006, terminó con un monumento de 1.500 ladrillos, con nombres de víctimas desaparecidas o asesinadas de todo el país. Esto fue posible porque llegaban personas con denuncias, con nombres, con fotos de sus víctimas y les hacían altares. Una acción que se hizo masiva, que contaba la historia de muchísimas víctimas en Colombia, que se manifestaba como una lucha política por la verdad, encuentra en un arte, muy ligado a la performancia, una alternativa para contar relatos ocultos, víctimas en silencio y que, al tiempo, hace memoria de muchos hechos que se dan en el país.

Estos hechos llegan a los medios de comunicación debido a su persistencia y masividad y hace que los ladrillos se conviertan en un símbolo de las víctimas del conflicto en el 
país. El uso de lo simbólico tiene fuerza y aún más si su posicionamiento llega a impactar sobre el espacio público. De esta manera, lo simbólico se convierte en masivo y tiene un gran valor sobre la sociedad y sobre la memoria, pues al construir memoria colectiva se hace imperante, por hacer que el dolor callado de los muertos de la violencia tenga circulación, tenga palabra y se convierta en un lugar en el que se pueda contar; un lugar en el que el olvido deje de ser el protagonista, para que esos hechos puedan darse a conocer y no vuelvan a repetirse. La instalación del monumento de las víctimas de Teatro Efímero, más allá del símbolo, se ha convertido en miles de relatos, en miles de memorias que cuentan una parte de la realidad del país: la realidad de las víctimas, de los muertos, de la violencia que sigue persistiendo en todo el país.

La iniciativa de los ladrillos con nombres de víctimas ha logrado llegar a diferentes rincones del país e incluso ha logrado ir a tierras extranjeras; es una acción que se ha multiplicado y que sin lugar a dudas se ha vuelto un símbolo de la memoria en Colombia, pues ha sido posible instalar monumentos de este tipo en plazas y parques, una vez al mes, en ciudades y pueblos como Barranquilla, Cartagena, Medellín, Pereira, Mocoa, Líbano (Tolima), Puerto Berrío (Antioquia), la Dorada (Caldas), la Gabarra (Norte de Santander), Tibú (Norte de Santander), Puerto Caicedo (Putumayo), Soacha (Cundinamarca), y en el extranjero ha logrado estar en Jijona y Vélez (España), en donde cada dos meses sacan el monumento con nombres de víctimas de la violencia en Colombia.

De acuerdo con esto, es importante dar cuenta, respecto al conflicto armado que enfrenta desde hace varias décadas el país y frente a procesos malogrados como el de la Ley de Justicia y Paz, de que una parte de la sociedad civil colombiana (en su mayoría víctimas) ha entrado fuertemente a reclamar y exigir el conocimiento de la verdad y la superación de la impunidad. Esto es así porque, en primer lugar, no se ha permitido que exista justicia y, en segundo lugar, lo que ha promovido es el olvido, pues dada la larga duración del conflicto, de alguna forma se ha permitido que el país se haya estructurado políticamente por la violencia. Uprimny (2010) señala la complejidad del conflicto en Colombia de la siguiente manera:

Entre quienes han analizado el caso colombiano, parece haber un consenso frente a que el proceso que experimenta el país no es un proceso transicional 
similar a los adelantados por otros países, precisamente por la complejidad social, política y económica del país. También coinciden en que no se trata de una transición completa (p. 328).

El proceso de justicia transicional que comenzó en el país con la implementación de la Ley 975, o de Ley Justicia y Paz de 2005, después de más de seis años de vigencia no parece ser una ley efectiva para un proceso de transición de un conflicto. Por el contrario, se ha creado un proceso de justicia transicional fragmentario, pues desde que esta se estableció no se han dado muestras, por parte del gobierno, de negociaciones con más actores alzados en armas; a su vez, ha dado serias muestras de que los paramilitares no se desmovilizaron en realidad y siguen operando con el nombre de bandas criminales (Rastrojos, Urabeños, Paisas, Águilas Negras, entre otros).

Ahora bien, si el proceso de justicia transicional tiene por objeto afrontar los abusos del pasado, jurídicamente, para dar cuenta de los responsables, de los hechos y de la verdad, la justificación y la legitimidad que estos deben tener se encuentra anclada en la memoria de lo que sucedió. Sin embargo, la memoria colectiva debe buscar ir más allá de la verdad, pues esta debe conducirnos a garantías de no repetición, y en un contexto como el de Colombia en el que el conflicto y los grupos armados ilegales siguen en vigencia es difícil que se generen nociones diferentes hacia futuro.

De acuerdo con esto, se hace evidente que es muy difícil hacer memoria en medio del conflicto; sin embargo, la existencia de lo que Jelin (2002) denomina "emprendedores de la memoria" hace pensar en la posibilidad de hacer memoria en medio del conflicto, pero no mediante leyes como la de Justicia y Paz ni mediante mecanismos institucionales, sino a través de movimientos sociales que disputan luchas por la reivindicación de las víctimas y la memoria, con nociones hacia el futuro, creando conciencia y opinión pública frente a la realidad del país.

En ese sentido, la búsqueda por parte de movimientos y organizaciones sociales, como la Fundación Rayuela y Teatro Efímero, ha desarrollado una apuesta desde las prácticas artísticas y la performancia para expresar las inconformidades sociales, presentando al arte como una posibilidad de resistencia y resiliencia. 
El hecho de encontrar en prácticas artísticas y alternativas como estas una vía distinta, en un contexto conflictivo y dejando cada vez más víctimas, es una labor que funciona como recurso para rememorar y no permitir que tantos hechos que ante la opinión pública se hacen invisibles sigan siéndolo; y a su vez, como prácticas con un intensión clara: que la impunidad no siga reinando. Así, el arte es una herramienta muy poderosa, en especial en un lugar donde la verdad y la justicia no han sido privilegiados y, más aún, donde se ocultan muchos de los sucesos violentos que han ocurrido; en un lugar donde no se conocen el nombre de muchas víctimas que aún siguen desaparecidas y que incluso sus familiares, por el temor a una retaliación, no se han atrevido a denunciar, porque grupos armados ilegales siguen gobernando gran parte de territorios del país.

Así pues, las prácticas performativas no solo son una forma de hacer memoria, sino también una forma de denuncia, de generación de opinión pública y de resistencia; en especial cuando los canales oficiales tanto jurídicos como mediáticos se encuentran cerrados por intereses particulares y, además, no han demostrado ser muy confiables en su operar.

Por lo tanto, el arte para construir memoria tiene una importancia gigantesca, cuando logra ser masiva y funciona, potencialmente, para elaborar memoria colectiva, para instaurarse en lugares públicos y llegar a todo tipo de personas que transitan por las víctimas, pues desde allí, como lo ha demostrado Teatro Efímero alrededor de sus acciones, es posible disputar una lucha política por la generación de opinión pública y por cuestionarse la construcción de un relato oficial, en el que se irrumpe la cotidianidad de las personas para dar a conocer hechos que a veces son invisibles a estos.

En el país, la construcción de memoria colectiva a través de manifestaciones artísticas y performativas, en un contexto en el que el conflicto armado y la violación a derechos humanos es continua, tiene un componente transformador, como lo revela Teatro Efímero, pues si a través de estas manifestaciones se logra provocar que la gente hable, que denuncie y que revele la verdad de lo que ha ocurrido en sus vidas frente a la violencia en Colombia, se está logrando que se den pasos para buscar la verdad y para que esa gran cantidad de víctimas que hay en la historia y que no se conocen, empiecen a hacer 
visibles y a hablar mediante estos correlatos alternativos que se proponen y que incita el arte. En estos casos, estas manifestaciones artísticas y performativas van más allá de lo estético y se convierten en una apuesta social y política.

Algo más importante aún: este tipo de manifestaciones artísticas y performativas no simplemente se quedan en la denuncia pública; por el contrario, tienen una posibilidad archivística muy grande, pues en acciones como El Siluetazo en Argentina o como Los Ladrillos de la Memoria en Colombia se abre la posibilidad de que la gente hable, de que pregunte por sus víctimas y de que en ese proceso se conviertan los ladrillos en un archivo que da cuenta de las víctimas del conflicto armado interno. Así como la memoria es indispensable para hablar de justicia, los archivos de rememoración son un elemento fundamental para que la impunidad no continúe. De esta manera, la memoria se convierte en una alternativa para que los hechos violentos y afrentosos que vive una sociedad no se repitan, para que esos hechos, al ser reconocidos, no se conviertan en un elemento de venganza, que es lo que también ha ocurrido en el país, pues no darle un lugar a la memoria en la construcción del país es permitir que estos hechos se sigan repitiendo constantemente.

En este sentido, la memoria se nos presenta como base fundamental para las luchas del presente, en la medida en que, al pensar en todas las víctimas que existen en el país, toda la impunidad que hay alrededor de estas muertes y lo que ha ocurrido en el pasado quede en el olvido; esto, de algún modo, les permite que los hechos se sigan repitiendo hacia futuro. De ahí la importancia de construir memoria y de buscar alternativas para hacerlo, encontrando una posibilidad aliada, muy fuerte, en el arte y la performancia. En ese sentido, la alternatividad, la búsqueda de correlatos y el posicionamiento en el espacio público son elementos fuertes de expresión y de denuncia, pero también elementos de relevancia para pensar gacia futuro y para llevar a la memoria en frente, lo que posibilita que estos hechos jamás se repitan, especialmente cuando los aparatos del Estado no logran dar respuesta a los actos violentos.

A su vez, es importante mostrar la capacidad que tiene el arte para hacer ver el mundo de otra manera, para contar lo que muchas veces es invisible a la opinión pública, para darle un significado a la realidad social y otra mirada a lo narrado por la historia oficial. Sin embargo, es importante aclarar que solo hasta ese lugar 
puede llegar el arte, pues "frente al trabajo que realiza la historia, el arte solo llegaría a ser un dato, otro recurso a las fuentes, que en ningún sentido desplaza el trabajo del historiador en la comprensión de los fenómenos sociales” (Aldana, 2009, p. 30).

\section{REFERENCIAS}

Aldana, J. (2009, mayo). La memoria colectiva y las prácticas artísticas. Revista Movimiento, 44, 24-31.

Beristain, C. (2000). Al lado de la gente: acompañamiento a comunidades en medio del conflicto armado. Bogotá: Cinep.

Ceballos, M. M. (2009). Comisiones de la verdad y transiciones de paz: Salvador, Guatemala, Suráfrica y posibilidades para Colombia. Medellín: La Carreta Editores.

Gerassi-Navarro, N. (1994). Naufragios y hallazgos de una voz narrativa en la escritura de Álvar Núñez Cabeza de Vaca. En Ortega, Amor y Vásquez (Eds.). Conquista y contraconquista, la escritura del nuevo mundo. México: Colegio de México y Brown University.

Jelin, E. (2002). Los trabajos de la memoria. Madrid: Siglo XXI.

Jelin, E. (2005). Exclusión, memorias y luchas políticas. En D. Mato (comp.). Cultura, política y sociedad: perspectivas latinoamericanas. Buenos Aires: Clacso.

Jelin, E. y Longoni, A. (comps.) (2005). Escrituras, imágenes y escenarios ante la represión. Madrid: Siglo XXI.

Longoni, A. y Bruzzone, G. (comps.) (2008). El Siluetazo. Buenos Aires: Adriana Hidalgo Editora.

Pinto, O, (2009, julio-diciembre). La lucha y la disputa: propuesta metodológica para el estudio de la política. Papel político, 14(2), 365-391. 
Schindel, E. (2009). Inscribir el pasado en el presente: memoria y espacio urbano. Politica y cultura, 31, 65-87. Recuperado de http://www.scielo.org.mx/scielo. php?script=sci_arttext\&pid=S0188-77422009000100005\&lng=es\&tlng=es

Tilly, C. (1998). Conflicto político y cambio social. En P. Ibarra y B. Tejerían (Eds.). Los movimientos sociales, transformaciones politicos y cambio cultural. España: Trotta.

Uprymny-Salazar, C. (2010, julio-diciembre). Saberse algo de memoria en el proceso transicional colombiano. International Law: Revista Colombiana de Derecho Internacional, 17, 323-353. 